\author{
Ralph Staerkle \\ Anne F. Mannion \\ Achim Elfering \\ Astrid Junge \\ Norbert K. Semmer \\ Nicola Jacobshagen \\ Dieter Grob \\ Jiri Dvorak \\ Norbert Boos
}

\section{Longitudinal validation of the Fear-Avoidance Beliefs Questionnaire (FABQ) in a Swiss-German sample of low back pain patients}

Received: 10 May 2003

Revised: 18 November 2003

Accepted: 28 November 2003

Published online: 9 January 2004

(C) Springer-Verlag 2004
R. Staerkle · N. Boos (凶)

Center for Spinal Surgery,

University of Zurich, Balgrist,

Forchstrasse 340,

8008 Zurich, Switzerland

Tel.: +41-1-3861273,

Fax: +41-1-3861609,

e-mail: Norbert.Boos@balgrist.ch

A. F. Mannion - A. Junge - D. Grob J. Dvorak

Spine Unit, Schulthess Klinik,

Zurich, Switzerland

A. Elfering - N. K. Semmer

N. Jacobshagen

Department of Psychology,

University of Berne, Berne, Switzerland
Abstract Work and activity-specific fear-avoidance beliefs have been identified as important predictor variables in relation to the development of, and treatment outcome for, chronic low back pain. The objective of this study was to provide a crosscultural German adaptation of the Fear-Avoidance Beliefs Questionnaire (FABQ) and to investigate its psychometric properties (reliability, validity) and predictive power in a sample of Swiss-German low back pain patients. Questionnaires from 388 operatively and non-operatively treated patients were administered before and 6 months after treatment to assess: socio-demographic data, disability (Roland and Morris), pain severity, fear-avoidance beliefs, depression (ZUNG) and heightened somatic awareness (MSPQ). Complete baseline and follow-up questionnaires were available from 255 participants. The corrected item-total correlations, coefficients of testretest reliability and internal consistencies of the two scales of the ques- tionnaire were highly satisfactory. In a confirmatory factor analysis (CFA), all items loaded on the appropriate factor with minor loadings on the other. Cross-sectional regression analysis with disability and work loss as the dependent variables yielded results that were highly comparable with those reported for the original version. Prognostic regression analysis replicated the findings for work loss. The cross-cultural German adaptation of the FABQ was very successful and yielded psychometric properties and predictive power of the scales similar to the original version. The inclusion of fear-avoidance beliefs as predictor variables in studies of low back pain is highly recommended, as they appear to have unique predictive power in analyses of disability and work loss.

Keywords Chronic low back pain . Fear-avoidance beliefs .

Cross-cultural adaptation - Disability . Work loss · Prediction

\section{Introduction}

The central role of fear of pain and consequent avoidance behaviour has gained increasing acceptance as a cognitive-behavioural pain dimension of utmost importance in relation to back pain $[9,12,16,18,23,24,28,30,36,47]$. This concept, which was introduced by Lethem in 1983 [28], proposes that avoidance behaviour results in an exaggerated pain perception [37]. Several studies have mean- while highlighted the effect of fear avoidance of physical activities and work on low-back pain and related disability $[10,13,17,19,25,31,41,45]$. Patients who believe that physical activity and work may be harmful tend to avoid these expectedly painful activities, with the consequence that the inappropriate avoidance behaviour is reinforced $[29,35,40,46,50]$.

On the basis of this conceptual background, Waddell et al. [47] developed a self-report questionnaire assessing fear-avoidance beliefs regarding the effects of physical 
activities and work on low back pain [47]. Several studies have explored the validity $[8,17,19,34,43]$ and the predictive power of the Fear-Avoidance Beliefs Questionnaire (FABQ) with regard to activities of daily living, work loss and treatment outcome in low back pain patients. Pfingsten et al. [39] reported on the validation of a German version of the FABQ. In contrast to the original version with two subscales, they suggested a three subscale version dividing the "work factor" into two factors, one concentrating on work as a cause of back pain and the other focusing on prognosis in relation to the ability to work.

There is increasing evidence in the literature that the FABQ is a valid and reliable tool that can be very helpful in predicting treatment outcome in LBP $[15,17,34$, 44]. So far, the validation has been performed in chronic LBP patient samples only. However, the validity of the questionnaire in predicting outcome (e.g., return to work, disability) of acute, subacute and chronic LBP patients has not been comprehensively addressed, particularly not in surgically treated patients. Furthermore, the fact that the same language is spoken in different countries does not preclude the existence of cultural differences between those countries, which can have a significant impact on study findings when a questionnaire is used in different countries [2, 26, 48]. It is therefore essential that outcome tools are evaluated in the specific target population $[4,21,22]$. The importance of cross-cultural adaptation of self-report measures has recently been summarised in a comprehensive review [3].

Therefore, the aim of the study was: (1) to develop a cross-cultural adaptation of the FABQ, (2) to investigate the psychometric properties of a German version of the FABQ (reliability, validity) and (3) to test the power in predicting treatment outcome in a Swiss-German population of patients with subacute and chronic LBP, including surgically treated patients.

Table 1 Sample characteristics

* Cases deleted because of lacking data on work parameters due to age-related retirement

\section{Materials and methods}

Study population

Patient screening for study participation began in March of 1999 and continued through April of 2000. Two hundred eighty patients were recruited from the spine centres of two orthopaedic hospitals and 108 patients from two chiropractic clinics, prospectively. Inclusion criteria were low back and/or leg pain for a duration of at least 1 month and fluency in the German language. Exclusion criteria were severe medical problems (e.g., tumour, infection, cardio-vascular disease) or musculoskeletal injuries. All patients who fulfilled the admission criteria were asked to complete the questionnaire during their visit to the hospital/chiropractic clinic for a consultation. A total of 388 patients filled in the first questionnaire and all were sent a follow-up questionnaire 6 months later. Two hundred fifty-five patients filled in and returned the follow-up questionnaire ( $n=133$ patients failed to return their second questionnaire), leading to a return rate of $66 \%$ (255/388). Details of the demographic characteristics of the patients are shown in Table 1. Note that participants with age-related retirement had to be excluded from some of the analyses, because they were not employed and therefore unable to complete items 6-16: this was the case for 86 patients from the 388 who filled in the first questionnaire, for 20 patients from the "drop-out" population who did not complete the follow-up questionnaire and for 66 patients from the longitudinal sample who filled in both questionnaires. In the longitudinal sample, a further 21 patients entered retirement during follow-up, thus preventing them from being included in the analyses of the longitudinal changes.

Development of a German FABQ version

The FABQ is a self-report-questionnaire that was developed in English with 16 items in two domains: (1) fear-avoidance beliefs about work and (2) fear-avoidance beliefs about physical activity. The development of a German version of the FABQ was accomplished as follows: (1) one person with native language German translated the FABQ into German, (2) one person with native language British English, a second person with native language American English and a third bilingual person (German, American English) independently translated the German version back into Eng-

\begin{tabular}{llll}
\hline & $\begin{array}{l}\text { Completed first } \\
\text { questionnaire }\end{array}$ & $\begin{array}{l}\text { Drop-outs at } \\
\text { the 6-month } \\
\text { follow-up (\%) }\end{array}$ & $\begin{array}{l}\text { Longitudinal sample } \\
\text { (both first and follow-up } \\
\text { questionnaire) }\end{array}$ \\
\hline$n$ & 388 & $133(34 \%)$ & 255 \\
Sex (m, f) & 172,216 & 59,74 & 113,142 \\
Age (mean \pm SD, range) & $54.2 \pm 16.3$, & $49.0 \pm 16.8$, & $56.9 \pm 15.5,18.8-86.9$ \\
Retirement baseline cases & $18.3-86.9$ & $18.3-85.4$ & 66 (further 21, retirement \\
excluded* & 87 & 20 & during follow-up) \\
Treatment (op., cons.) & 257,131 & 70,63 & 187,68 \\
Diagnosis & & & \\
Disc herniation & 59 & 23 & 36 \\
Spinal stenosis & 144 & 33 & 111 \\
Discopathy & 54 & 19 & 35 \\
Facet syndrome & 18 & 8 & 10 \\
Segmental instability & 60 & 23 & 37 \\
Non-specific low back pain & 53 & 27 & 26 \\
\hline
\end{tabular}


Table 2 German version of the Fear-Avoidance Beliefs Questionnaire (FABQ)

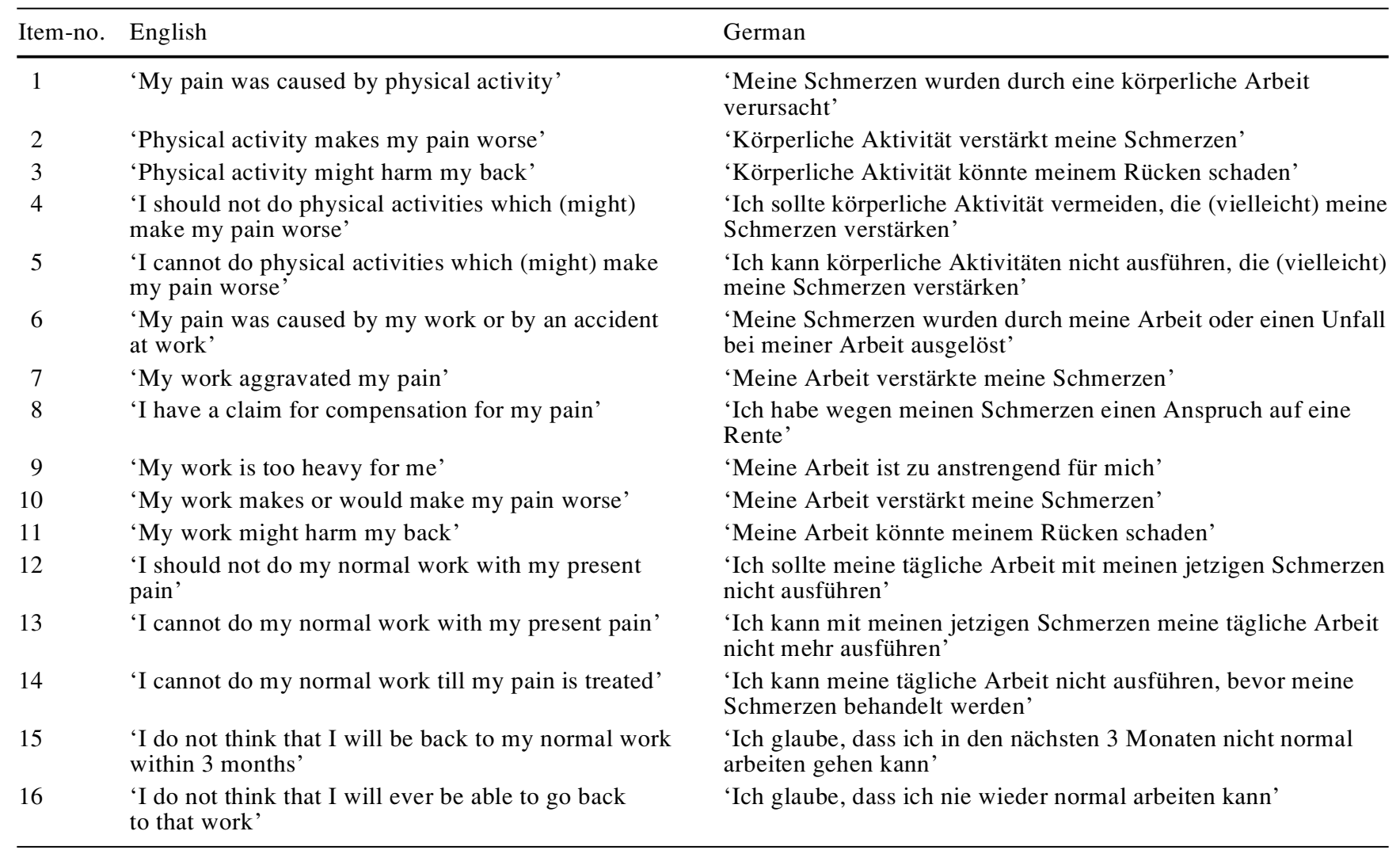

Table 3 Questionnaires

\begin{tabular}{|c|c|c|c|}
\hline Domains/questionnaires & $\begin{array}{l}\text { Number of } \\
\text { items }\end{array}$ & Response format & References \\
\hline \multicolumn{4}{|l|}{ Fear-Avoidance Beliefs Questionnaire } \\
\hline FABQ1 (work beliefs) & 7 & Seven-point Likert scale & $\begin{array}{l}\text { Waddell et al. } 1993 \text { [47]; } \\
\text { Pfingsten et al. } 2000 \text { [39] }\end{array}$ \\
\hline FABQ2 (activity beliefs) & 4 & & \\
\hline \multicolumn{4}{|l|}{ Present pain index } \\
\hline At present & 3 & $\begin{array}{l}\text { Sum index (six-point Likert } \\
\text { scale, each) }\end{array}$ & Exner 1998 [14] \\
\hline \multicolumn{4}{|l|}{ At best (last 7 days) } \\
\hline \multicolumn{4}{|l|}{ At worst (last 7 days) } \\
\hline Pain duration & 1 & Five-point Likert scale, each & \\
\hline Roland and Morris Disability Questionnaire & 24 & Yes/no & Roland and Morris 1983 [42] \\
\hline Zung Depression scale & 20 & Four-point Likert scale & Zung et al. 1965 [49] \\
\hline Modified Somatic Perception-Questionnaire & 13 & Four-point Likert scale & $\begin{array}{l}\text { Main 1983 [32]; Mannion et al. } \\
1999 \text { [33] }\end{array}$ \\
\hline Work absence & 1 & Days off work & Patrick et al. 1995 [38] \\
\hline
\end{tabular}

lish, (3) a further person with native language British English compared the original version with the re-translated versions and (4) based on these translations, a final version was developed in conference (Table 2).

\section{Reliability assessment}

The short-term reliability was assessed in a similar manner to that reported by Waddell et al. [47]. A total of 30 out-patients were asked to complete the FABQ questionnaire, twice within $48 \mathrm{~h}$, without receiving any active treatment between these two occasions. As in the original work by Waddell [47], the time interval was 
chosen as the optimal to minimise clinical or cognitive changes, but to make it unlikely that patients would remember their previous answers.

\section{Longitudinal validation}

The same questionnaires as those described by Waddell [47] were used for analysing the correlation of fear-avoidance beliefs with various clinical variables, with two exceptions: the severity of pain was measured with a six-point Likert scale rather than a visual analogue scale, and the duration of pain ("pain history") was measured with a five-point Likert scale ranging from "1 to 3 months" to "more than 5 years". Work loss (days off work) was assessed with regard to the last month, not with respect to present work loss or work loss in the past year.

Further self-reported measures included the Roland and Morris disability score [42], the Modified Somatic Perception questionnaire [32] and the Zung Depression Scale [49]. A six-point Likert scale was used to inquire about low back pain at the moment and about the most and least severe pain during the last 7 days [14]. A question from the National Health Interview Survey was used to measure the work absence in the last month [38]. All questionnaires have been reported and validated in the German and/or English literature (Table 3 ).

Data analysis and statistics

The analyses employed were identical to those used by Waddell et al. [47] in validating the English version of the FABQ. The psychometric properties of the scale were examined using test-retest reliability coefficients, the intraclass correlation and kappa coefficients. Cronbach's alpha coefficients were calculated to measure the internal consistency of the scales. A confirmatory factor analysis (CFA) with baseline data was carried out to examine main and marginal item loadings and the respective variance explained by the two factors. In the longitudinal sample a CFA on the baseline and follow-up data was carried out using structural equation modelling (SEM). AMOS 4.0 was used to test the measurement equivalence of the constructs across measurement points [1]. Using SEM the items are indicators of the latent variable, which is equivalent to a factor. An error term is estimated for each indicator, and errors in longitudinal measurement models can be correlated. This approach allows a more precise test of a confirmatory model and its stability over time. Note that change during recovery may involve (1) a change in intensity of fear avoidance beliefs, i.e., change in the level of FABQ scales, but also (2) a reappraisal of which aspects of work exactly, and how work and activity, might influence physical health. For instance, patients with acute pain may 'overgeneralise' the association between all work/physical activities and back pain. In this case, their initial scores would show very similar item loadings within the subscales. When asked again, after their pain has subsided somewhat and they have shown progress in their general ability to move again, they may be much better able to differentiate between the specific items, i.e., their item loadings would change. In repeated measurements, the same item for a questionnaire may therefore be explained to a different extent by a given factor ("beta change") [20]. This sort of change may even affect the stability of the factorial solution and thus render change in the mean levels difficult to interpret. For this reason it is desirable that, for psychometric instruments, the factorial structure and item loadings are stable in factor analysis. The stability of item loadings was tested for the FABQ by constraining the loadings of each indicator to be equal at the two measurement points and then testing whether this restricted model was as valid as an unrestricted one.

Univariate relationships between the FABQ scales and clinical outcome variables were examined using Pearson product-moment correlations. A multivariate analysis of variables that statistically explained the variance in surgical and conservative treatment outcome (work absence, disability) included both baseline predictor variables and follow-up outcome variables. In a hierarchical regression model, control variables (age, gender) were entered into the model in a first step, then pain severity was entered in a second step, the FABQ-scales were entered in a third step, and finally depression followed in a fourth step. This multivariate regression model is similar to that reported by Waddell et al. [47]. Analyses were performed cross-sectionally and longitudinally. In longitudinal hierarchical regression analysis, the baseline values of the dependent variables entered the model first, and the following steps were then similar to those for the cross-sectional analysis.

\section{Results}

\section{Item characteristics}

Similar to the original version, a skewed distribution was found for item 8; over $60 \%$ of the patients answered "completely disagree". This item was therefore excluded from factor analyses. The other items were approximately normally distributed and item-total correlations were satisfactory (baseline: 0.51-0.76; follow-up: 0.49-0.83).

\section{Scale structure}

In accordance with the original version [47], the two-factor model of the FABQ was tested in a confirmatory factor analysis. Factor 1 (FABQ1) relates to fear-avoidance beliefs about the relationship between work and low back pain and factor 2 (FABQ2) concerns fear-avoidance beliefs about the relationship between physical activity and low back pain. In accordance with the criteria reported by Waddell et al. [47], item 1 was excluded, because of inconsistent factor loadings $(<0.45$ on appropriate factor). Because item 8 showed a very skewed distribution, this item was also excluded. Item 13 and item 14 seemed to be enquiring about the same issue $(r=0.82)$ and were both correlated with item 12; they were therefore excluded because of redundancy as in Waddell's original study [47]. In constrast to the original study, no argument was found to exclude item 16 for redundancy. Internal consistencies (Cronbach alpha) of both scales were highly satisfactory at baseline [FABQ1 (items 6, 7, 9, 10, 11, 12 and 15): 0.89, FABQ2 (items 2, 3, 4 amd 5): 0.82] and follow-up (FABQ1: 0.91, FABQ2: 0.83) (i.e., when examining the same items finally recommended for inclusion by Waddell et al.) [47].

At baseline, both factors had Eigenvalues larger than the value of 1 ("Kaiser-Guttman criterion"), indicating that both factors contributed to explaining the variance. The first factor (FABQ1) had an Eigenvalue of 7.10 (Wadell 4.81) and the second factor (FABQ2) a value of 1.56 (Waddell 1.82). The percent variance explained was 47.30 for FABQ1 (Waddell: 43.7) and 10.38 for FABQ2 (Waddell: 16.5) (Table 4). 
Table 4 Factor analysis of FABQ items

\begin{tabular}{lll}
\hline \multicolumn{3}{l}{ Two-factorial } \\
\cline { 2 - 3 } & $\begin{array}{l}\text { FABQ 1 loadings } \\
\text { "work" }(>0.15)\end{array}$ & $\begin{array}{l}\text { FABQ 2 loadings } \\
\text { "activity" }(>0.15)\end{array}$ \\
\hline FABQ-items at baseline $(n=264)$ & \\
1 & 0.22 & 0.35 \\
2 & 0.28 & 0.71 \\
3 & 0.23 & 0.78 \\
4 & & 0.83 \\
5 & 0.20 & 0.76 \\
6 & 0.57 & \\
7 & 0.76 & 0.20 \\
9 & 0.74 & 0.23 \\
10 & 0.77 & 0.26 \\
11 & 0.70 & 0.36 \\
12 & 0.81 & 0.28 \\
13 & 0.72 & 0.28 \\
14 & 0.72 & 0.28 \\
15 & 0.75 & 0.19 \\
16 & 0.67 & 0.30 \\
Eigenvalue (percent & $7.10(47.30)$ & $1.56(10.38)$ \\
variance explained) & & \\
\hline
\end{tabular}

Test-retest reliability

Retesting the patients with subacute low back pain $48 \mathrm{~h}$ after the first assessment showed that $65 \%$ of the answers were identical. The average kappa for all 16 items was 0.54 (range $0.34-0.68, P<0.01$ for each coefficient). The average weighted kappa statistic was 0.76 (range 0.48$0.89, P<0.01$ for each coefficient). The Pearson productmoment correlation coefficients for the repeated measurements of the two sub-scales were 0.91 (FABQ1) and 0.84 (FABQ2). The intraclass correlations coefficients were comparably high (0.91 in FABQ1 and 0.83 in FABQ2). The differences between both measurements were not significantly different from zero (CI FABQ1:0.12 \pm 0.23 , CI FABQ2: $0.06 \pm 0.26)$. The coefficient of repeatability (CR) [5] was calculated as 1.96 times the standard deviation of the differences between the two measurements. The CR showed that $97.5 \%$ of the differences were smaller than 1.5 points on the 7-point Likert scale (FABQ1, $\mathrm{CR}=1.26$, FABQ2 CR $=1.45$ ).

\section{Simultaneous confirmatory factor analysis}

The structural equation modelling approach was chosen to test the stability of a two-factor structure. In this analysis, the longitudinal sample was reduced to 168 participants because 87 retired (for age-related reasons) patients were excluded to prevent (potential) biases on work vs. activity subscales of the FABQ. Missing values in the FABQ items reduced the longitudinal sample to 132 participants. The two-factorial measurement model showed a satisfac-
Table 5 Confirmatory factor analysis of FABQ scales at baseline and follow-up $(n=132)$

\begin{tabular}{lccccc}
\hline Measurement model & $\chi 2$ & df & $P$ & $\chi 2 / d f$ & RMSEA \\
\hline $\begin{array}{l}\text { Two factorial model (Wadell et al. 1993) } \\
\text { (1) Freely estimated }\end{array}$ & 385.86 & 192 & 0.00 & 2.01 & 0.09 \\
$\begin{array}{l}\text { item loadings } \\
\begin{array}{l}\text { (2) Same item loadings } \\
\text { at baseline and follow-up }\end{array}\end{array}$ & 401.46 & 202 & 0.00 & 1.99 & 0.09 \\
\hline
\end{tabular}

Results from structural equation models of baseline and follow-up data, allowing for autocorrelations of errors across time. $\chi 2=\mathrm{Chi}^{2}$ square value indicates the minimum discrepancy between empirical covariance structures and those implied by the model. $d f$ Degrees of freedom; $P$ probability of the discrepancy; $\chi 2 / d f$ minimum discrepancy divided by its degrees of freedom, as an indicator of fit, values $>2.00$ represent inadequate fit [11]; $R M S E A$ root mean square error of approximation, a measure of fit that takes into account the population moments rather than sample moments, should not be greater than 0.10 [7]

Table 6 Correlations between FABQ subscales in simultaneous confirmatory factor analysis. Correlations as estimated between latent variables of baseline and follow-up FABQ subscales in a structural equation approach

\begin{tabular}{llllll}
\hline & $\begin{array}{l}\text { All implied } \\
\text { correlations }- \\
\text { estimates }\end{array}$ & Baseline & Follow-up \\
\hline Baseline & FABQ1, work beliefs & - & & \\
& FABQ2, activity beliefs & 0.64 & - & & \\
Follow-up & FABQ1, work beliefs & 0.74 & 0.49 & - & \\
& FABQ2, activity beliefs & 0.41 & 0.54 & 0.57 & - \\
\hline
\end{tabular}

tory fit when baseline and follow-up data were combined in a common model $[\chi 2(192)=385.86, \chi 2 / \mathrm{df}=2.01, P=$ 0.00 , root mean square error of approximation (RMSEA) $=0.09$, see notes in Table 5) $]$ and the common model still fitted well when equality constraints were set on factor loadings and factor interrelations $[\chi 2(202)=401.46, \chi 2 / \mathrm{df}=$ $1.99, P=0.00$, RMSEA $=0.09]$. The equality constraints did not lead to a decrease in fit in comparison with the unrestrained model shown $\left[\Delta \chi^{2}(10)=15.60, P=0.11\right)$. Stability coefficients of both latent variables were high, but showed that inter-individual differences for work beliefs were more stable than those for activity beliefs (Table 6).

\section{Responsiveness}

We calculated an effect size for the responsiveness of the FABQ to intervention by dividing the difference between the mean baseline and the mean follow-up score by the standard deviation of the difference in scores [(mean follow-up score-mean baseline score)/SD of the difference in scores] [6]. Responsiveness was low to moderate for FABQ1 (work, effect size: 0.33) and for FABQ2 (physical activity, effect size: 0.41 ). 
Table 7 Bivariate correlations of fear-avoidance beliefs and clinical variables
$* P<0.05 ; * * P<0.01$

$* * * P<0.001$

Table 8 Summary of hierarchical regression analysis of low back disability and work loss at baseline

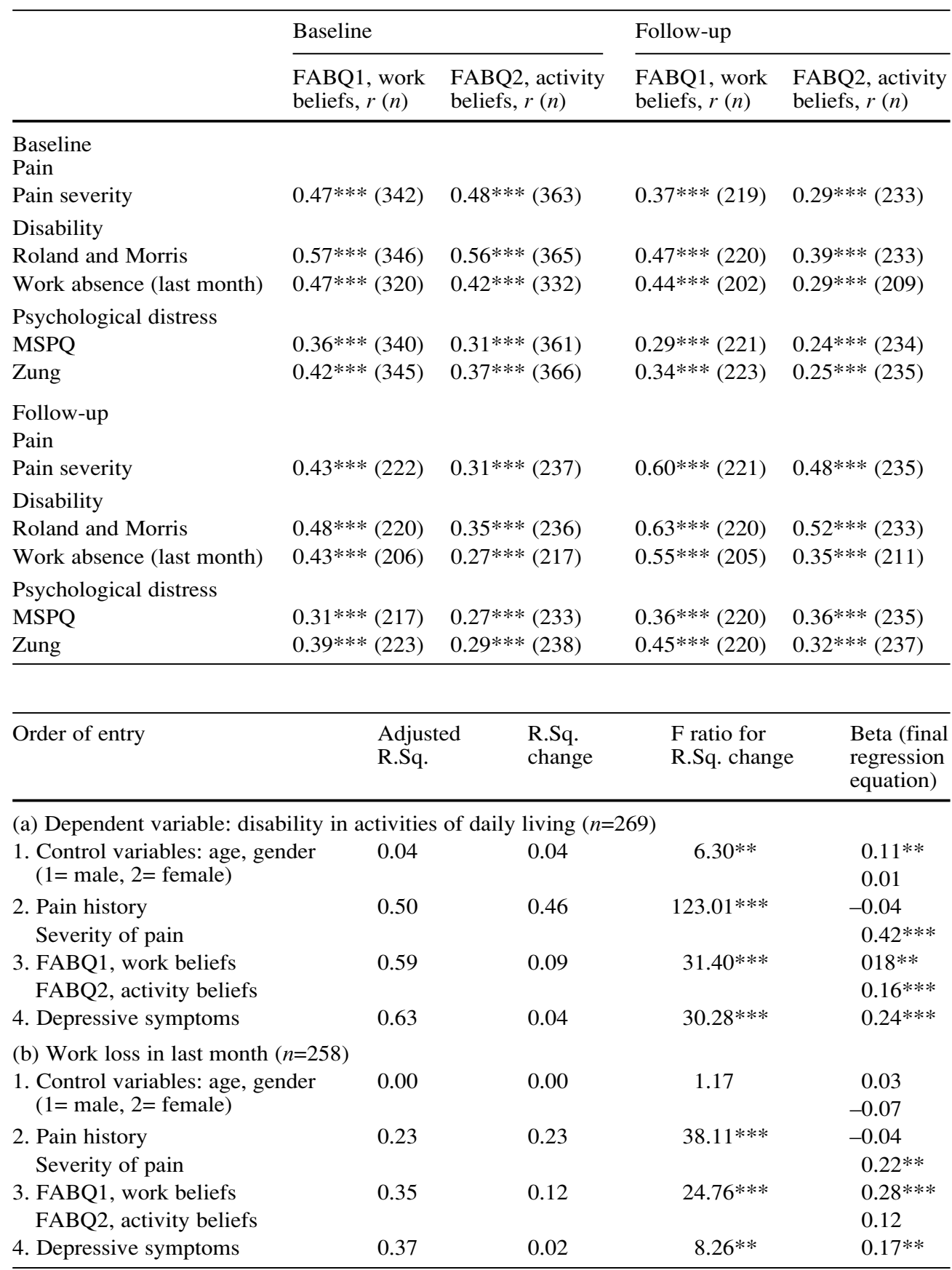

Depressive symptoms
$* P<0.05 ; * * P<0.01$ $* * * P<0.001$
In agreement with the findings for the English version of the questionnaire [47], disability [expressed either as self-reported disability in everyday activities (Roland Morris) [42] or as work loss in the last month] was the attribute that correlated most strongly with the FABQ1 and FABQ2 scores. The relationships were generally somewhat stronger for FABQ1 (work), although highly significant also for FABQ2 (physical activity).

Moderate correlations $(r=0.31-0.45)$ of the same order as those reported by Waddell et al. [47] were observed between ported by Waddell et al. [47] (5\% common variance). 
Table 9 Summary of longitudinal hierarchical regression analysis of low back disability and work loss at follow-up

\begin{tabular}{lllll}
\hline Order of entry & $\begin{array}{l}\text { Adjusted } \\
\text { R.Sq. }\end{array}$ & $\begin{array}{l}\text { R.Sq. } \\
\text { change }\end{array}$ & $\begin{array}{l}\text { F ratio for } \\
\text { R.Sq. change }\end{array}$ & $\begin{array}{l}\text { Beta (final } \\
\text { regression } \\
\text { equation) }\end{array}$ \\
\hline
\end{tabular}

(a) Dependent variable: disability in activities of daily living (Roland Morris, 1983) $(n=153)$

\begin{tabular}{|c|c|c|c|c|}
\hline \multirow{2}{*}{$\begin{array}{l}\text { 1. Disability in activities (baseline) } \\
\text { 2. Control variables: age, gender } \\
(1=\text { male, } 2=\text { female })\end{array}$} & 0.44 & 0.44 & $121.12 * * *$ & $0.34 * * *$ \\
\hline & 0.47 & 0.03 & $5.58 * *$ & $\begin{array}{l}0.21 * * \\
0.02\end{array}$ \\
\hline $\begin{array}{l}\text { 3. Pain history } \\
\text { Severity of pain }\end{array}$ & 0.51 & 0.04 & $7.34 * *$ & $\begin{array}{l}0.13^{*} \\
0.19 *\end{array}$ \\
\hline $\begin{array}{l}\text { 4. FABQ1, work beliefs } \\
\text { FABQ2, activity beliefs }\end{array}$ & 0.52 & 0.01 & 2.32 & $\begin{array}{l}0.11 \\
0.04\end{array}$ \\
\hline 5. Depressive symptoms & 0.54 & 0.02 & $4.72 *$ & $0.15^{*}$ \\
\hline $\begin{array}{l}\text { (b) Work loss in last month }(n=149) \\
1 . \text { Work loss (baseline) }\end{array}$ & 0.20 & 0.20 & $39.09 * * *$ & $0.26^{* *}$ \\
\hline $\begin{array}{l}\text { 2. Control variables age, gender } \\
(1=\text { male, } 2=\text { female })\end{array}$ & 0.20 & 0.00 & 0.37 & $\begin{array}{l}0.01 \\
0.02\end{array}$ \\
\hline $\begin{array}{l}\text { 3. Pain history } \\
\text { Severity of pain }\end{array}$ & 0.23 & 0.03 & $3.54 *$ & $\begin{array}{l}0.05 \\
0.14\end{array}$ \\
\hline $\begin{array}{l}\text { 4. FABQ1, work beliefs } \\
\text { FABQ2, activity beliefs }\end{array}$ & 0.25 & 0.02 & $3.17 *$ & $\begin{array}{l}0.20^{*} \\
0.03\end{array}$ \\
\hline 5. Depressive symptoms & 0.25 & 0.00 & 0.06 & 0.02 \\
\hline
\end{tabular}

5. Depressive symptoms
$* P<0.05 ; * * P<0.01$; $* * * P<0.001$
FABQ (each sub-scale) and MSPQ, and between FABQ (each sub-scale) and ZUNG self-rated depression [49].

Multivariate analyses of factors explaining disability and work loss

In cross-sectional analysis, the scales of the FABQ proved to be significant independent predictors of disability and work loss, when the results were controlled for the effects of pain history and pain intensity (Table 8 ). The corresponding longitudinal test of change examined the outcome at follow-up in relation to predictor variables at baseline, whilst simultaneously controlling for the value of the outcome variable at baseline [27]. In longitudinal prediction, only FABQ work beliefs appeared to be a meaningful predictor of days off-work in the last month, when days off-work at baseline were controlled for. In longitudinal prediction of self-rated disability, the contribution of the FABQ scales did not reach statistical significance. However, the stability in disability (from pre- to posttreatment) explained quite a large proportion of the variance $(44 \%$; Table 9 , step 1$)$, leaving little variation to be explained by other predictor variables.

\section{Discussion}

In a Swiss population of 388 patients with sub-acute and chronic low back pain, a cross-cultural (German) adaptation of the Fear-Avoidance Beliefs Questionnaire (FABQ) [47] is suggested and evaluated with regard to reliability and validity.

\section{Scale structure}

In accordance with the original version, a two-factor model of the FABQ concerning work and physical activity was used. The internal consistencies of both scales were highly satisfactory at baseline and follow-up.

The structural equation modelling approach was chosen to test the stability of the two-factor structure. The subscales showed high correlations across time, indicating a high stability. The inter-individual differences in work beliefs were more stable than those of activity beliefs. Interrelations between latent variables $(0.64$ and 0.57$)$ are higher than reported in Waddell et al. [47] ( $r=0.39)$. In the German version of the FABQ developed by Pfingsten et al. [39], which was not yet published when the current study was conducted, a three-factorial solution was proposed, leaving the activity-scale unchanged (but including item 1) and subdividing the work-scale into a 'work as a cause' factor (items 6, 7, 9, 10 and 11) and a 'work' prognosis factor (items 12 to 16).

In the present study, the fit of the Pfingsten et al. [39] three-factor model was acceptable if factor loadings were not constrained to be equal across all points in time $(\chi 2=828.06, \mathrm{df}=375, \chi 2 / \mathrm{df}=2.21, P=0.00, \mathrm{RMSEA}=0.10)$. However, unlike the Waddell et al. [47] model, the threefactor model was not robust with respect to equality constraints of factor loadings, showing less factorial consistency in time. The fit of the restrained three-factor model was noticeably different from a three-factor model in which the parameters were freely estimated $(\chi 2=860.98$, $\left.\mathrm{df}=390, \Delta \chi^{2}{ }_{(15)}=32.92, P<0.01\right)$. Moreover, in our data, the "work cause" and "work prognosis" factors of Pfingsten et al. [39] were more closely associated than they were 
shown to be in the original paper [39] (our data at baseline: 0.79; our data at follow-up: 0.71; Pfingsten et al. [39] 0.67). This question needs to distinguish between the two work factors, especially when - as in the present data the patterns of correlation between 'work as a cause' and 'work prognosis' with important third variables were rather similar. Furthermore, methodologically, the distinction between these highly related scales would create problems of multi-collinearity in predictor analyses.

\section{Reproducibility}

The retest within $48 \mathrm{~h}$ in the outpatient group showed that $65 \%$ of the questions were answered identically. This result is similar to the findings of Waddell [47] (71\% identical answers), and is thus considered adequate. Correlation coefficients for the test-retest reliability of the two subscales were 0.91 and 0.84 . Waddell [47] obtained retest correlations of 0.95 and 0.88 .

\section{Relationship of FABQ to clinical variables}

Correlations between the FABQ and the clinical variables (pain, disability) and psychological distress were highly statistically significant. The correlation coefficients were generally similar to those reported by Waddell et al. [47], with the exceptions that pain severity and FABQ (each subscale) correlated much more strongly with each other in the present study and that FABQ2 (physical activity) generally correlated more strongly with all the clinical variables than it had done in the study of Waddell et al. [47]. This may be the result of the inclusion of patients who were undergoing surgery and who therefore had a specific diagnosis for their LBP (with a structural correlate) rather than "non-specific" LBP (i.e., without a structural correlate). In agreement with Pfingsten et al. [39], in the threefactorial solution, 'work prognosis' was more closely correlated with the Modified Somatic Perception questionnaire [32] and the Zung Depression Scale [49] than "work as a cause'. This was also true for disability and work loss in cross-sectional correlation, but rather decreased in longitudinal correlation (for instance $r=0.39$ between 'work as a cause' at baseline and work loss at follow-up and $r=0.48$ for 'work prognosis' at baseline and work loss at follow-up).

\section{Prediction of disability and work loss}

There is now substantial evidence that fear-avoidance beliefs are important factors in the chronification of low back pain $[24,29,45,47]$ and strongly influence the patient's perception of pain-related disability [34]. The results from the present study, using the present German version of the FABQ, tend to confirm this finding. Fearavoidance beliefs were shown to be associated both with self-rated disability and work loss. Multiple hierarchical regression analysis of disability and work loss in crosssectional data replicated the results of Waddell et al. [47] very closely. The scales of the FABQ proved to be significantly related to disability if the results were controlled for the duration and intensity of low back pain. Only fearavoidance beliefs about work appeared to be meaningfully associated with days off work in the last month, again, a result that replicated the findings of Waddell et al. [47]. In addition, longitudinal prediction of work loss at follow-up showed that pre-treatment fear-avoidance beliefs about work predicted work loss after treatment, when the baseline association between predictor variables and work loss was controlled for. Noteworthy, using the Pfingsten et al. [39] factors as predictor variables in prognostic regression, there was no advantage of the 'work prognosis' factor over 'work as a cause', for no FABQ subscale turned out as a significant predictor in this analysis (but even showing the strongest partial regression coefficient for 'work as a cause').

In conclusion, the cross-cultural (German) adaptation of the FABQ was successful and yielded psychometric properties and predictive power of the scales similar to the original English version. The inclusion of fear-avoidance beliefs as predictor variables in studies of low back pain is highly recommended, as they appear to have unique predictive power in analyses of disability and work loss.

Acknowledgements We would like to thank Prof. Dr. A. Benini, Dr. Daniel Mühleman, Dr. Peter Braun, Dr. Beat Wächli and Dr. Peter Kraenzlin for the referral of their patients into this study.

\section{References}

1. Arbuckle JL, Wothke W (1999) Amos 4.0 user's guide. Small Waters Coporation, Chicago

2. Arguedas O, Andersson-Gare B, Fasth A, et al (1997) Development of a Costa Rican version of the Childhood Health Assessment Questionnaire. J Rheumatol 24:2233-2241
3. Beaton DE, Bombardier C, Guillemin F, et al (2000) Guidelines for the process of cross-cultural adaptation of self-report measures. Spine 25:3186-3191

4. Berkanovic E (1980) The effect of inadequate language translation on Hispanics' responses to health surveys. Am J Public Health 70:1273-1276
5. Bland JM, Altman DG (1999) Measuring agreement in method comparison studies. Stat Methods Med Res 8:135160

6. Bortz J, Döring N (1995) Forschungsmethoden und Evaluation. Springer, Berlin, Heidelberg New York

7. Browne MV, Cudeck R (1993) Alternative ways of assessing model fit. Testing structural equation models. Sage, Newbury Park, CA 
8. Buchbinder R, Jolley D, Wyatt M (2001) 2001 Volvo Award Winner in clinical studies: effects of a media campaign on back pain beliefs and its potential influence on management of low back pain in general practice. Spine 26:2535-2542

9. Buer N, Linton SJ (2002) Fear-avoidance beliefs and catastrophizing: occurrence and risk factor in back pain and ADL in the general population. Pain 99:485-491

10. Burton AK, Waddell G, Tillotson KM, et al (1999) Information and advice to patients with back pain can have a positive effect. A randomized controlled trial of a novel educational booklet in primary care. Spine 24:2484-2491

11. Byrne BM (1989) A primer of LISREL: basic applications and programming for confirmatory factor analytic models. Springer, New York Heidelberg Berlin

12. Cardon G, De Bourdeaudhuij I, De Clercq D (2002) Knowledge and perceptions about back education among elementary school students, teachers, and parents in Belgium. J Sch Health 72:100-106

13. Crombez G, Vlaeyen JW, Heuts PH, et al (1999) Pain-related fear is more disabling than pain itself: evidence on the role of pain-related fear in chronic back pain disability. Pain 80:329-339

14. Exner V (1998) Lebensqualität bei chronischen RückenschmerzpatientInnen (Quality of life in chronic back-pain patients). University of Basel, Switzerland

15. Flynn T, Fritz J, Whitmann J, et al (2002) A clinical prediction rule for classifying patients with low back pain who demonstrate short-term improvement with spinal manipulation. Spine 27:2835-2843

16. Fordyce WE, Shelton JL, Dundore DE (1982) The modification of avoidance learning pain behaviors. J Behav Med 5:405-414

17. Fritz JM, George SZ, Delitto A (2001) The role of fear-avoidance beliefs in acute low back pain: relationships with current and future disability and work status. Pain 94:7-15

18. Fritz JM, George SZ (2002) Identifying psychosocial variables in patients with acute work-related low back pain: the importance of fear-avoidance beliefs. Phys Ther 82:973-983

19. George SZ, Fritz JM, Erhard RE (2001) A comparison of fear-avoidance beliefs in patients with lumbar spine pain and cervical spine pain. Spine 26: 2139-2145

20. Golembiewski RT, Billingsley K, Yeager S (1976) Measuring change persistency in human affairs: types of change generated in OD designs. J Appl Behav Sci 12:133-157
21. Gonzalez VM, Stewart A, Ritter PL, et al (1995) Translation and validation of arthritis outcome measures into Spanish. Arthritis Rheum 38:1429-1446

22. Gonzalez-Calvo J, Gonzalez VM, Lorig K (1997) Cultural diversity issues in the development of valid and reliable measures of health status. Arthritis Care Res 10:448-456

23. Hanada EY (2003) Efficacy of rehabilitative therapy in regional musculoskeletal conditions. Best Pract Res Clin Rheumatol 17:151-166

24. Hasenbring M, Hallner D, Klasen B (2001) Psychological mechanisms in the transition from acute to chronic pain: over- or underrated? Schmerz 15:442-447

25. Holm I, Friis A, Storheim K, et al (2003) Measuring self-reported functional status and pain in patients with chronic low back pain by postal questionnaires: a reliability study. Spine 28:828-833

26. Jacob T, Baras M, Zeev A, et al (2001) Low back pain: reliability of a set of pain measurement tools. Arch Phys Med Rehabil 82:735-742

27. Kasl SV, Jones BA (2003) An epidemiological perspective on research design, measurement, and surveillance. Handbook of occupational health psychology. APA, Washington

28. Lethem J, Slade PD, Troup JD, et al (1983) Outline of a fear-avoidance model of exaggerated pain perception. Behav Res Ther 21:401-408

29. Linton SJ, Andersson T (2000) Can chronic disability be prevented? A randomized trial of a cognitive-behavior intervention and two forms of information for patients with spinal pain. Spine 25:2825-2831 (discussion 2824)

30. Linton SJ, Ryberg M (2001) A cognitive-behavioral group intervention as prevention for persistent neck and back pain in a non-patient population: a randomized controlled trial. Pain 90:83-90

31. Linton SJ, Vlaeyen J, Ostelo R (2002) The back pain beliefs of health care providers: are we fear-avoidant? J Occup Rehabil 12:223-232

32. Main CJ (1983) The modified somatic perception questionnaire (MSPQ). J Psychosom Res 27:503-514

33. Mannion AF, Muntener M, Taimela S, et al (1999) A randomized clinical trial of three active therapies for chronic low back pain. Spine 24:2435-2448

34. Mannion AF, Junge A, Taimela S, et al (2001) Active therapy for chronic low back pain: part 3. Factors influencing self-rated disability and its change following therapy. Spine 26:920-929

35. McCracken LM, Gross RT, Aikens J, et al (1996) The assessment of anxiety and fear in persons with chronic pain: a comparison of instruments. Behav Res Ther 34:927-933
36. Moore JE, Von Korff M, Cherkin D, et al (2000) A randomized trial of a cognitive-behavioral program for enhancing back pain self care in a primary care setting. Pain 88:145-153

37. Nickel R, Egle UT, Schwab R (2002) Diagnostic subgroups and psychosocial characteristics in chronic non-malignant pain patients referred to an out-patient pain center. Psychother Psychosom Med Psychol 52:378-385

38. Patrick DL, Deyo RA, Atlas SJ, et al (1995) Assessing health-related quality of life in patients with sciatica. Spine 20:1899-1909

39. Pfingsten M, Kroner-Herwig B, Leibing E, et al (2000) Validation of the German version of the fear-avoidance beliefs questionnaire (FABQ) [In Process Citation]. Eur J Pain 4:259-266

40. Pfingsten M (2001) Functional restoration - it depends on an adequate mixture of treatment. Schmerz 15:492-498

41. Rivier G (2001) Common lumbago and returning to work: various thoughts about a complex problem. Rev Med Suisse Romande 121:423-430

42. Roland M, Morris R (1983) A study of the natural history of back pain. Part I: development of a reliable and sensitive measure of disability in low-back pain. Spine 8:141-144

43. Swinkels-Meewisse EJ, Swinkels RA, Verbeek AL, et al (2003) Psychometric properties of the Tampa Scale for kinesiophobia and fear-avoidance beliefs questionnaire in acute low back pain. Man Ther 8:29-36

44. Vlaeyen JW, Linton SJ (2000) Fearavoidance and its consequences in chronic musculoskeletal pain: a state of the art. Pain 85:317-332

45. Vlaeyen JW, de Long J, Geilen M, et al (2002) The treatment of fear of movement/(re)injury in chronic low back pain: further evidence of the effectiveness of exposure in vivo. Clin $\mathrm{J}$ Pain 18:251-261

46. Vowles KE, Gross RT (2003) Workrelated beliefs about injury and physical capability for work in individuals with chronic pain. Pain 101:291-298

47. Waddell G, Newton M, Henderson I, et al (1993) A Fear-Avoidance Beliefs Questionnaire (FABQ) and the role of fear-avoidance beliefs in chronic low back pain and disability. Pain 52:157168

48. Wiesinger GF, Nuhr M, Quittan M, et al (1999) Cross-cultural adaptation of the Roland-Morris questionnaire for German-speaking patients with low back pain. Spine 24:1099-1103

49. Zung WW, Richards CB, Short MJ (1965) Self-rating depression scale in an outpatient clinic. Further validation of the SDS. Arch Gen Psychiatry 13: 508-515

50. Zusman M (1997) Instigators of activity intolerance. Man Ther 2:75-86 